МАТЕРИАЛЫ VI-ГО СЪЕЗДА

ГЕРПЕТОЛОГИЧЕСКОГО ОБЩЕСТВА ИМ. А. М. НИКОЛЬСКОГО

УДК 597;598

Н.Б. Ананьева

РОССИЙСКАЯ ГЕРПЕТОЛОГИЯ В ХХІ ВЕКЕ: АНАЛИЗ ДЕЯТЕЛЬНОСТИ ГЕРПЕТОЛОГИЧЕСКОГО ОБЩЕСТВА ИМЕНИ А.М.НИКОЛЬСКОГО ЗА 2000-2015 гГ. ПО МАТЕРИАЛАМ СЪЕЗДОВ ОБЩЕСТВА*

В статье дается обзор деятельности герпетологического общества им. А. М. Никольского в 2000-2015 гг., а также анализ изменений тематики, направлений, подходов и методов исследований в СССР и в современной России. Библиогр. 5 назв. Табл. 2.

Ключевые слова: Герпетологическое общество им. А.М.Никольского, амфибии, рептилии, направления, итоги и перспективы исследований.

\title{
N.B. Ananjeva
}

\section{RUSSIAN HERPETOLOGY IN THE $21^{\text {st }}$ CENTURY: ANALYSIS OF ACTIVITY OF THE A. M. NIKOLSKY HERPETOLOGICAL SOCIETY FROM 2000-2015 BASED ON THE PROCEEDINGS OF SOCIETY'S MEETINGS}

\section{Zoological Institute RAS, 1, Universitetskaya nab., St. Petersburg, 199164, Russian Federation; natalia.ananjeva@zin.ru}

The article provides an analysis of the publication activity in the A. M. Nikolsky Herpetological Society as a reflection of herpetological research activity in the $21^{\text {st }}$ century (2000-2015), as well as changes in research topics, trends of approaches and methods in the Soviet Union and modern Russia. Refs 5. Tables 2 .

Keywords: A.M.Nikolsky, Herpetological Society amphibians, reptiles, directions, results and perspectives of research.

Герпетологическое общество им. А. М. Никольского при РАН (далее - Герпетологическое общество) является правопреемником Всесоюзного герпетологического комитета при научном совете Академии Наук СССР «Биологические основы освоения, реконструкции и охраны животного мира», который занимался данной тематикой с 1962 по 1989 г. Его основной задачей была координация разносторонних исследований в области изучения земноводных и пресмыкающихся в различных регионах страны. В этот период было проведено семь Всесоюзных герпетологиче-

А.Б. Ананьева (natalia.ananjeva@zin.ru): Зоологический институт РАН, Российская Федерация, 199164, Санкт-Петербург, Университетская наб., 1.

* Работа выполнена при поддержке РФФИ (проекты № 15-29-02457 офи_м и № 15-04-01730).

() Санкт-Петербургский государственный университет, 2016 
ских конференций: в Ленинграде (1964, 1969, 1973, 1977), Ашхабаде (1981), Ташкенте (1985) и Киеве (1989), а их материалы опубликованы в шести тематических сборниках «Вопросы герпетологии». В 1989 г. в Киеве на последней очередной (седьмой) Всесоюзной герпетологической конференции было принято решение о создании Герпетологического общества, это решение было утверждено учредительным съездом в Пущино в 1991 г., а впоследствии (в декабре 1993 г.) - Российской академией наук. Новому обществу было присвоено имя выдающегося русского герпетолога, одного из основателей отечественной науки о земноводных и пресмыкающихся, профессора Александра Михайловича Никольского (1858-1941).

В декабре (4-7) 2000 г. в Пущино на базе Института биофизики клетки РАН состоялся Первый съезд Герпетологического общества (совместно с Обществом охраны амфибий и рептилий, Москва), собравший более 120 участников из различных регионов России и ряда стран СНГ. По объективным причинам конференции Герпетологического общества не собирались в течение десяти лет после его создания; в этот период в мировой герпетологии произошли революционные изменения в методических и методологических подходах к научным исследованиям, появились новые направления. Российские герпетологи, их коллеги из стран СНГ, члены Герпетологического общества работали в различных, в том числе приоритетных и весьма перспективных направлениях, и результаты их деятельности были наглядно представлены в пленарных, устных и стендовых докладах. С этого времени были проведены шесть герпетологических съездов: в Пущино-на-Оке (2000, 2006, 2015), Санкт-Петербурге (2003), Казани (2009) и Минске (2012), а материалы пяти из них были опубликованы в тематических сборниках «Вопросы герпетологии», изданных с 2001 по 2012 г. [1-5]. Материалы Шестого съезда публикуются в настоящем выпуске.

Сравнение материалов съездов, опубликованных в названных сборниках, позволяет создать своего рода «срез» количественных параметров и тематики герпетологии в России и других странах бывшего СССР (табл. 1). С 2000 г. происходило постепенное увеличение числа участников конференций, а количество публикаций в последние годы несколько возрастает.

Таблица 1. Динамика числа участников герпетологических съездов и опубликованных материалов

\begin{tabular}{|l|c|c|c|c|c|c|c|c|}
\hline \multicolumn{1}{|c|}{ Год } & 1973 & 1977 & 2000 & 2003 & 2006 & 2009 & 2012 & 2015 \\
\hline Участники & 164 & 236 & 119 & 151 & 126 & 132 & 165 & 165 \\
\hline Публикации & 141 & 196 & 170 & 52 & 68 & 54 & 82 & - \\
\hline
\end{tabular}

П р и м е ч а н и е. Количество участников и публикаций в 2003 г. указано только для членов Общества им. А. М.Никольского, съезд которого проводился совместно с Конгрессом Европейского Герпетологического общества.

Анализ публикаций позволяет также зафиксировать тематический профиль исследований в XXI веке по сравнению с наиболее продуктивной Всесоюзной герпетологической конференцией 1977 г. (табл. 2).

В последние годы удалось преодолеть тенденцию сокращения исследований в области морфологии, но несколько сократилась интенсивность работ в области экологии и поведения амфибий и рептилий. Сравнение профиля публикаций в раз- 
Таблица 2. Сравнительный анализ тематики герпетологических исследований в XXI веке

\begin{tabular}{|l|c|c|c|c|c|c|c|c|c|c|c|c|c|c|}
\hline Год (съезд) & М & Пал & СНФ & И & Ф & ЭПА & ЭПР & ВД & Р3 & Т & ОХ & П & РН & ВСЕГО \\
\hline 1977 & 29 & 6 & 8 & 0 & 18 & 43 & 40 & 8 & 17 & 20 & 1 & 4 & 2 & 196 \\
\hline 2000 (I) & 30 & 6 & 9 & 1 & 11 & 50 & 29 & 6 & 16 & 1 & 12 & 2 & 3 & 170 \\
\hline 2003 (II) & 11 & 1 & 4 & 1 & 1 & 12 & 6 & 9 & 2 & 0 & 3 & 2 & 1 & 52 \\
\hline $2006(\mathrm{III})$ & 8 & 0 & 17 & 0 & 5 & 20 & 16 & 5 & 5 & 0 & 3 & 1 & 2 & 68 \\
\hline $2009(\mathrm{IV})$ & 9 & 0 & 4 & 1 & 4 & 10 & 9 & 2 & 4 & 0 & 2 & 2 & 4 & 54 \\
\hline $2012(\mathrm{~V})$ & 17 & 3 & 7 & 3 & 4 & 13 & 16 & 8 & 5 & 2 & 3 & 0 & 1 & 82 \\
\hline
\end{tabular}

П р и м еч а н и е. М - морфология; Пал - палеонтология; СНФ - систематика, номенклатура и филогения; И - история; Ф - фаунистика; ЭПА - экология и поведение амфибий; ЭПР экология и поведение рептилий; ВД - видообразование; Р3 - распространение и зоогеография; $\mathrm{T}$ - токсикология; OX - охрана, включая криоконсервацию; П - паразитология; $\mathrm{PH}$ - разведение в неволе. Римскими цифрами отмечены порядковые номера герпетологических конференций им. А. М.Никольского.

личные годы наглядно демонстрирует, что систематика и филогения земноводных и пресмыкающихся с различным уровнем дивергенции остается в фокусе ряда исследовательских групп российских и украинских герпетологов, успехи которых в значительной степени определяются диверсификацией классических и современных молекулярно-генетических методов. Расширяется география герпетологических исследований, которая в настоящее время охватывает ранее малоизученные регионы Евразии, большие успехи достигнуты российскими герпетологами в изучении биоразнообразия тропической Азии.

Приходится с сожалением констатировать, что по сравнению с герпетологическими исследованиями в СССР сейчас практически исчезло целое междисциплинарное направление в области токсикологии и других аспектов изучения ядов амфибий и рептилий. В частности, были широко развернуты перспективные исследования в области применения змеиных ядов в распознавании нарушений в свертывающей системе крови, изучение состава, биологического действия и применения змеиных ядов (см. табл. 2). Вопросам токсикологии на Всесоюзных конференциях были посвящены пленарный доклад и специальное секционное заседание, связанное с теоретической и практической значимостью изучения и применения ядов и медицинского значения змеиных укусов, публиковались материалы не менее 20 докладов. С начала XXI века было опубликовано лишь два доклада, а на последней конференции в 2015 г. были представлены всего три доклада. Остается надеяться, что вновь возникнет интерес к этой сфере исследования, что позволит осуществить планы создания межведомственной проблемной лаборатории по изучению стандартизации и выпуску диагностических реактивов и лечебных препаратов из змеиных ядов.

Как важный инновационный тренд следует рассматривать широкое применение информационных технологий в исследованиях распространения, экологии и создании баз данных различного назначения: особенно важным аспектом такого рода исследований нужно назвать развернутое в последние годы создание интегрированных информационных систем коллекционных депозитариев.

Исследовательская активность российских герпетологов отражена также в публикациях специального издания Герпетологического общества, издаваемого на 
базе Зоологического института РАН и Саратовского государственного университета им. Н. Г. Чернышевского, «Современная Герпетология».

\section{Литература}

1. Вопросы герпетологии. Материалы Первого съезда герпетологического общества им. А. М. Никольского. 4-7 декабря 2000 г., Пущино-на-Оке. Пущино-Москва, 2001. 360 с.

2. Вопросы герпетологии. Материалы Третьего съезда Герпетологического общества им. А. М. Никольского. 9-13 октября 2006 г., Пущино-на-Оке. Санкт-Петербург, 2008. 468 с.

3. Вопросы герпетологии. Материалы Четвертого съезда Герпетологического общества им. А. М. Никольского. 12-17 октября 2009 г., Казань. Санкт-Петербург, 2011. 336 с.

4. Вопросы герпетологии. Материалы Пятого съезда Герпетологического общества им. А. М. Никольского. 24-27 сентября 2012 г., Минск, Беларусь. Минск: ИООО «Право и экономика», 2012. 382 с.

5. Herpetologia Petropolitana. Proceedings of the $12^{\text {th }}$ Ordinary General Meeting of Societas Europaea Herpetologica. 12-16 August 2003. Saint Petersburg, Russia. 340 p.

Для цитирования: Ананьева Н.Б. Российская герпетология в XXI веке: анализ деятельности герпетологического общества имени А.М.Никольского за 2000-2015 гг. по материалам съездов общества // Вестник Санкт-Петербургского университета. Серия 3. Биология. 2016. Вып. 3. С.6-9. DOI: 10.21638/11701/spbu03.2016.301

\section{References}

1. Voprosy gerpetologii. Materialy Pervogo s"ezda gerpetologicheskogo obshchestva im. A. M. Nikol'skogo. 4-7 dekabria $2000 \mathrm{~g}$. [The problems of Herpetology. Proc. $1^{\text {th }}$ Meet. Nikolsky Herpetological Society. December 4-7, 2000]. Pushchino-na-Oke, Pushchino-Moskva, 2001. 360 p. (In Russian)

2. Voprosy gerpetologii. Materialy Tret'ego s"ezda Gerpetologicheskogo obshchestva im. A. M. Nikol'skogo. 9-13 oktiabria $2006 \mathrm{~g}$. [The problems of Herpetology. Proc. $3^{\text {th }}$ Meet. Nikolsky Herpetological Society. October 9-13, 2006]. Pushchino-na-Oke, Saint Petersburg, 2008. 468 p. (In Russian)

3. Voprosy gerpetologii. Materialy Chetvertogo s"ezda Gerpetologicheskogo obshchestva im. A. M. Nikol'skogo. 12-17 oktiabria 2009 g. [The problems of Herpetology. Proc. $4^{\text {th }}$ Meet. Nikolsky Herpetological Society. October 12-17, 2009]. Kazan, Saint Petersburg, 2011. 336 p. (In Russian)

4. Voprosy gerpetologii. Materialy Piatogo s"ezda Gerpetologicheskogo obshchestva im. A. M. Nikol'skogo. 24-27 sentiabria $2012 \mathrm{~g}$. [The problems of Herpetology. Proc. $5^{\text {th }}$ Congress Alexander M. Nikolsky Herpetological Society. September 24-27, 2012]. Minsk, Belarus, Minsk, IOOO "Pravo i ekonomika", 2012. 382 p. (In Russian)

5. Herpetologia Petropolitana. Proceedings of the 12th Ordinary General Meeting of Societas Europaea Herpetologica. 12-16 August 2003, Saint Petersburg, Russia. 340 p.

For citation: Ananjeva N. B. Russian herpetology in the $21^{\text {st }}$ century: analysis of activity of the A. M. Nikolsky Herpetological Society from 2000-2015 based on the proceedings of society's meetings. Vestnik of Saint Petersburg University. Series 3. Biology, 2016, issue 3, pp. 6-9. DOI: 10.21638/11701/spbu03.2016.301

Статья поступила в редакцию 25 января 2016 г., принята 30 января 2016 г.

Сведения об авторе:

Ананьева Наталия Борисовна - доктор биологических наук, профессор

Ananjeva Natalia B. - Doctor of Biology, Professor 